\title{
Factors associated with free adult preventive health care utilization among physically disabled people in Taiwan: nationwide population-based study
}

Suh-May Yen ${ }^{1,2,3}$, Pei-Tseng Kung ${ }^{4}$ and Wen-Chen Tsai ${ }^{i^{*}}$

\begin{abstract}
Background: Few previous studies have specifically addressed the health care utilization situation of the physically disabled. This study aimed to investigate the utilization of free adult preventive health care for physically disabled people and its' affecting factors.

Methods: The data was obtained from three nationwide databases from 2006 to 2008. This study comprised 329,264 physically disabled people in Taiwan above the age of 40 who had eligible health checks during 2008. We employed descriptive statistics to analyze the use and rate of free preventive health care use by physically disabled adults. Logistic regression analysis was used to explore the factors that affect physically disabled adults' use of free adult preventive health care.

Results: $16.37 \%$ of the physically disabled adults used free adult preventive health care. Women (17.66\%), married (17.16\%), a junior high education level (17.89\%), and mildly disabled adults (18.77\%) had the highest use rate among various participant subgroups. The variables that significantly influenced the use of free adult preventive health care by the physically disabled included gender, age, education, marital status, urbanization of the residence areas, monthly payroll, aboriginal status, catastrophic illnesses status, relevant chronic diseases, and severity of disability.

Conclusions: Physically disabled using preventive health care tend to be low. Governments should use the media to reinforce propagation and education of these services to specific, low-utilization groups, and encourage doctors to actively provide preventive health care to communities.
\end{abstract}

Keywords: Physical disability, Disability, Adult health examination, Preventive health care

\section{Background}

Because nerve damage from an injury in physically disabled people causes chronic pain [1,2], depression [3], and other complications, these patients lack the motivation to participate in various activities. Physically disabled people often have a sedentary lifestyle, leading to become overweight and obese [4-6]. Being overweight and obese cause changes in the modes of carbohydrate metabolism, increasing the prevalence of diabetes, hyperlipidemia,

\footnotetext{
*Correspondence: wtsai@mail.cmu.edu.tw

'Department of Health Services Administration, China Medical University, No. 91 Hsueh-Shih Road, Taichung 40402, Taiwan

Full list of author information is available at the end of the article
}

hypertension, and cardiovascular disease [7,8]. A 2002 study showed that people with disabilities in their lower extremities are 2.5 times the overweight and obesity ratio of average persons, and $40 \%$ of people with chronic spinal cord injuries are overweight or obese [9].

Nosek et al. [10] found that physically disabled women had 4 times the likelihood of suffering from diabetes, and 2 times the likelihood of suffering from hypertension than do average women. Studies have shown that those with spinal cord injuries have a higher prevalence of diabetes and coronary heart disease [11-13]. Poliomyelitis patients have a higher hyperlipidemia occurrence than the average person, and typically have two 
or more coronary artery disease risk factors [14]. Until the end of 2011, Taiwan's physically disabled population (386,217 people) accounted for $1.66 \%$ of the total population, and constituted the group with the most people $(35.09 \%)[15,16]$ with mentally or physically disabilities (handicapped).

The disabled population has increased annually, consuming the government's health care and long-term care resources and producing a significant financial burden and challenge for society [17-20]. Maciosek et al. [21] believed that if the government expanded the promotion of free preventive health care utilization for all population, it would save US \$3.7 billion annually in medical care expenditures. Increasing the utilization of free preventive health care can delay disease progression, reduce the severity of the disease, and effectively reduce medical expenses derived from complications [22-25]. Eliminating the inequities of disabled persons in health and medical care is the goal of the US Healthy People for 2020 [26].

Besides the cancer screening, Taiwan Health Promotion Administration provides at least six free preventive health care programs, including mammography, pap smear test, prenatal examination for pregnant women, children preventive health services, adult preventive health services, and children dental examination with fluoride varnish. The adult free preventive health care includes physical examinations, health education, and blood and urine tests. Adults aged 40 and above are legible this free service, but different age groups have varying frequency limits.

Because of the low mobility of physically disabled people, their medical care time is lengthened. Difficulties in receiving free preventive health care among the disabled people would lead to delay in receiving appropriate medical care. Previous studies showed gender, marital status [16], educational level, age, income, health status, severity of disability, and urbanization level would influence the utilization of preventive health services for the disabled people [27]. Much of the literature related to the disabled people focused on the secondary conditions of the disability, leaving a scarcity of research on the preventive health care needs of this disabled population. Few previous studies have specifically addressed the health care utilization situation of the physically disabled. This study used physically disabled people as participants to explore their free adult preventive health care utilization and its related factors, and to serve as a reference for adjusting preventive health policies for disadvantaged groups.

\section{Methods}

\section{Data source and participants}

The premise for the use of free adult preventive health care includes (1) people suffering from poliomyelitis and older than 35 years (use once a year), (2) people aged between 40 to 64 years (once every three years), and (3) people aged 65 or older (once a year). The data were obtained from three national databases, and all three national databases were managed by the government. The Disabled People Registry File (2008) obtained from the Ministry of the Interior, the free preventive health care file (2006 to 2008) provided from the Health Promotion Administration and the National Health Insurance Research Database (2006 to 2008) released by the Ministry of Health and Welfare.

This study comprised 329,264 physically disabled people in Taiwan above the age of 40 who had eligible health checks during 2008. Among these, 153,117 were mildly disabled, 128,201 were moderately disabled, 44,097 were severely disabled, and 3,849 were extremely severely disabled. Among the 35 to 39 year-old disabled adults, since there was no way to distinguish who were poliomyelitis persons in the Disabled People Registry File and we could not analyze the utilization rate and likelihood of using preventive health care, this group was excluded when the analyses were conducted.

In the present study, demographic characteristics and severity of disability were obtained from the Disabled People Registry File (2008). Socioeconomic status, health status, and the environmental factor were merged from the National Health Insurance Research Database, which is publicly available. The information of using the free adult preventive health care among the physically disabled people was identified from the free preventive health care file (2006 to 2008).

After we applied and were approved to use these three databases, the personal identifications including ID number and name were used to exactly match all people's data or information in these three databases in the Statistics Center of the Ministry of Health and Welfare, Taiwan. All personal information could be completely linked among these three national databases. All individual's identification information has been deleted and personal privacy was protected in using these data. This study was approved by the research ethics committee of China Medical University and Hospital (IRB No. CMU-REC-101-012).

\section{Variables description}

The variables in this study were (1) demographic characteristics (i.e., gender, age, marital status, education, aboriginal status); (2) socioeconomic status (i.e., monthly insured payroll); (3) health status (i.e., catastrophic illness/injury, type of chronic illnesses including 15 comprehensive categories of chronic diseases such as cancer, endocrine and metabolic disease, mental illness, disease of nervous system, disease of circulatory system, disease of respiratory system, disease of digestive system, disease of urinary system, disease of skeletal and muscular system and connective tissue, disease of eyes and auxiliary organs, 
infectious disease, congenital malformation, skin and subcutaneous tissue disorders, disease of blood and bloodforming organs, and disease of ear and mastoid process), severity of disability (i.e., very severe, severe, moderate, and mild); and (4) environmental factors (i.e., urbanization level of residence area, URA; eight levels: Level 1 being the highest urbanized areas, and Level 8 being the lowest). The dependent variable that whether the physically disabled persons used the adult preventive health care was identified in the year 2008 for those aged 65 or older(once per year) and identified in the period of 2006- 2008 for those aged between 40 and 64 (once every three years). The other relevant independent variables, including demographic, socioeconomic, health status, severity of disability, and environmental factors were obtained in the year 2008 from three national databases. The chronic disease groups used in this study were based on "the Range of Chronic Diseases" in the National Health Insurance Research Database. The chronic diseases listed in the Range of Chronic Diseases were defined by the Bureau of National Health Insurance in Taiwan, which consisted of 16 categories of chronic diseases. (Additional file 1). Since the "others" category had very few patients in the disabled people, this study excluded the "others" category in our analysis.

\section{Statistical analysis}

This study used descriptive statistics analysis, chi-squared test, and multiple logistic regression analysis to explain the relationship between the variables. The first step used descriptive statistics to analyze the physically disabled people's free adult preventive health care utilization quantity and ratio, focusing on their demographic characteristics, socioeconomic status, health status, environmental factors, and other variables. The second step used the chi-square test to compare the difference in physically disabled people's use of free preventive health care. Since all variables had a $\mathrm{p}$ value $<0.05$ in the chi-squared test in Table 1, we placed all variables into the logistic regression analysis to explore the factors that affected the use of free adult preventive health care among the physically disabled people.

Under the criteria for assessing model fit, the loglikelihood statistics for the fitted model indicated the model fitted well. This study used statistical software package SAS version 9.3 as an analysis tool. Statistics less than $P<0.05$ were significant.

\section{Results}

\section{Physically disabled people's basic information}

Table 1 showed that there were 329,264 physically disabled people during 2006 to 2008. Over half of these were male $(58.2 \% ; \mathrm{n}=191,566)$. In the age category, most participants were older than or equivalent to 70 years of age $(34.2 \% ; n=112,521)$, followed by participants between
45 and $49(14.4 \%, \mathrm{n}=47,257)$. More than half of the participants were married $(58.5 \% ; \mathrm{n}=192,456)$. Participants with education levels less than or equivalent to elementary school accounted for the majority $(51.1 \%$; $n=168,180)$, followed by junior high level $(14.9 \%$; $\mathrm{n}=49,103)$. Regarding monthly insured payroll, the insured dependent population accounted for the majority (i.e., children and spouses; $34.0 \% ; n=111,998)$. There were few people of aboriginal status, only accounting for $2.2 \%(n=7,105)$. Mildly disabled $(46.5 \% ; n=153,117)$ was the largest group in the physical disability severity level category.

\section{Physically disabled people's free preventive health care utilization}

In this study, $16.4 \%(n=53,913)$ of the physically disabled utilized free adult preventive health care (Table 1). Men and women's utilization rates were $15.5 \%$ and $17.7 \%$ $(P<0.05)$, respectively. The men's utilization rate was slightly lower than the women's. Regarding age distribution, the 50 to 64 year-old group had the higher physically disabled utilization rate, more than $20 \%$. The 60 to 64 year-old group had the greatest utilization (25.6\%). Married people had a higher utilization rate (17.2\%) than did the others $(15.2 \%-15.7 \%, P<0.05)$. For education, junior high and senior (vocational) high school had greater utilization rates: $17.9 \%$ and $17.1 \%$, respectively. Those with URA Level 8 had the greatest utilization rate (19.1\%), and Level 1 had the smallest (10.9\%). For income, those with a monthly insured payroll of NT \$30,300 to 36,300 (22.3\%) had the highest rate. Those with aboriginal status had higher utilization rates $(24.1 \%)$ than did non-aborigines $(16.2 \%, P<0.05)$. In the relevant chronic diseases category, people with "diseases of the ear and mastoid process" (21. 2\%) had a higher utilization rate, and utilization rate for those with cancer $(13.1 \%)$ was less than those without cancer $(16.5 \%, P<0.05)$. Regarding severity of disability, those with mild disability had the highest utilization rate $(18.8 \%)(P<0.05)$.

\section{Factors related to use of free adult preventive health care} As shown in Table 2, this study found that gender, age, education, marital status, urbanization of residence area (URA), monthly insured payroll, aboriginal status, catastrophic illnesses status, relevant chronic diseases, and severity of the disability had significant effects on the use of free adult preventive health care by the physically disabled $(P<0.05)$.

The logistic regression analysis showed that physically disabled men had a slightly lower free adult preventive health care utilization rate, only 0.82 times that of women $(95 \% \mathrm{CI}=0.80-0$ 84). In the age aspect, using 40 to 44 year olds as a reference group, the 60 to 64 age group's utilization rate was 1.41 times greater than the reference rate $(\mathrm{OR}=1.41,95 \% \mathrm{CI}=1.34-1.48)$. The lowest rate was among those older than or equivalent to 70 years, which 
Table 1 Use of adult preventive health services among the physical disability: basic characteristics and bivariate analysis

\begin{tabular}{|c|c|c|c|c|c|c|c|}
\hline \multirow[b]{2}{*}{ Variable name } & \multirow[b]{2}{*}{$\mathrm{N}=329264$} & \multirow[b]{2}{*}{$\%$} & \multicolumn{2}{|l|}{ Used } & \multicolumn{2}{|l|}{ Did not use } & \multirow{2}{*}{$\begin{array}{l}x^{2} \\
p \text {-value }\end{array}$} \\
\hline & & & $n_{1}=53913$ & $\%$ & $n_{2}=275351$ & $\%$ & \\
\hline Overall rate of use & & & & 16.4 & & 83.6 & \\
\hline Gender & & & & & & & $<.001^{*}$ \\
\hline Female & 137698 & 41.8 & 24323 & 17.7 & 113375 & 82.3 & \\
\hline Male & 191566 & 58.2 & 29590 & 15.5 & 161976 & 84.6 & \\
\hline Age & & & & & & & $<.001^{*}$ \\
\hline $40-44$ years & 20795 & 6.3 & 3224 & 15.5 & 17571 & 84.5 & \\
\hline $45-49$ years & 47257 & 14.4 & 8401 & 17.8 & 38856 & 82.2 & \\
\hline $50-54$ years & 44941 & 13.7 & 9039 & 20.1 & 35902 & 79.9 & \\
\hline $55-59$ years & 37922 & 11.5 & 8516 & 22.5 & 29406 & 77.5 & \\
\hline $60-64$ years & 30296 & 9.2 & 7746 & 25.6 & 22550 & 74.4 & \\
\hline 65-69 years & 35532 & 10.8 & 4549 & 12.8 & 30983 & 87.2 & \\
\hline$\geq 70$ years & 112521 & 34.2 & 12438 & 11.1 & 100083 & 89.0 & \\
\hline Educational level & & & & & & & $<.001^{*}$ \\
\hline Elementary school and under & 168180 & 51.1 & 27179 & 16.2 & 141001 & 83.8 & \\
\hline Junior high school & 49103 & 14.9 & 8784 & 17.9 & 40319 & 82.1 & \\
\hline Senior (vocational) high school & 45345 & 13.8 & 7740 & 17.1 & 37605 & 82.9 & \\
\hline Junior college and university or above & 23908 & 7.3 & 3491 & 14.6 & 20417 & 85.4 & \\
\hline Unclear & 42728 & 13.0 & 6719 & 15.7 & 36009 & 84.3 & \\
\hline Marital status & & & & & & & $<.001^{*}$ \\
\hline Married & 192456 & 58.5 & 33027 & 17.2 & 159429 & 82.8 & \\
\hline Unmarried & 30357 & 9.2 & 4630 & 15.3 & 25727 & 84.8 & \\
\hline Divorced or widowed & 14209 & 4.3 & 2234 & 15.7 & 11975 & 84.3 & \\
\hline Unclear & 92242 & 28.0 & 14022 & 15.2 & 78220 & 84.8 & \\
\hline Level of urbanization ${ }^{a}$ & & & & & & & $<.001^{*}$ \\
\hline Level one & 28966 & 8.8 & 3158 & 10.9 & 25808 & 89.1 & \\
\hline Level two & 66465 & 20.2 & 10372 & 15.6 & 56093 & 84.4 & \\
\hline Level three & 47461 & 14.4 & 7860 & 16.6 & 39601 & 83.4 & \\
\hline Level four & 28536 & 8.7 & 4503 & 15.8 & 24033 & 84.2 & \\
\hline Level five & 51000 & 15.5 & 9053 & 17.8 & 41947 & 82.3 & \\
\hline Level six & 39836 & 12.1 & 6739 & 16.9 & 33097 & 83.1 & \\
\hline Level seven & 43417 & 13.2 & 7717 & 17.8 & 35700 & 82.2 & \\
\hline Level eight & 23583 & 7.2 & 4511 & 19.1 & 19072 & 80.9 & \\
\hline Monthly insured payroll & & & & & & & $<.001^{*}$ \\
\hline Insured dependents & 111998 & 34.0 & 14367 & 12.8 & 97631 & 87.2 & \\
\hline$<15,840$ & 66219 & 20.1 & 10338 & 15.6 & 55881 & 84.4 & \\
\hline $16,500-22,800$ & 100385 & 30.5 & 18934 & 18.9 & 81451 & 81.1 & \\
\hline $24,000-28,800$ & 14864 & 4.5 & 3288 & 22.1 & 11576 & 77.9 & \\
\hline $30,300-36,300$ & 13942 & 4.2 & 3113 & 22.3 & 10829 & 77.7 & \\
\hline $38,200-45,800$ & 12768 & 3.9 & 2643 & 20.7 & 10125 & 79.3 & \\
\hline $48,200-57,800$ & 9088 & 2.8 & 1230 & 13.5 & 7858 & 86.5 & \\
\hline
\end{tabular}


Table 1 Use of adult preventive health services among the physical disability: basic characteristics and bivariate analysis (Continued)

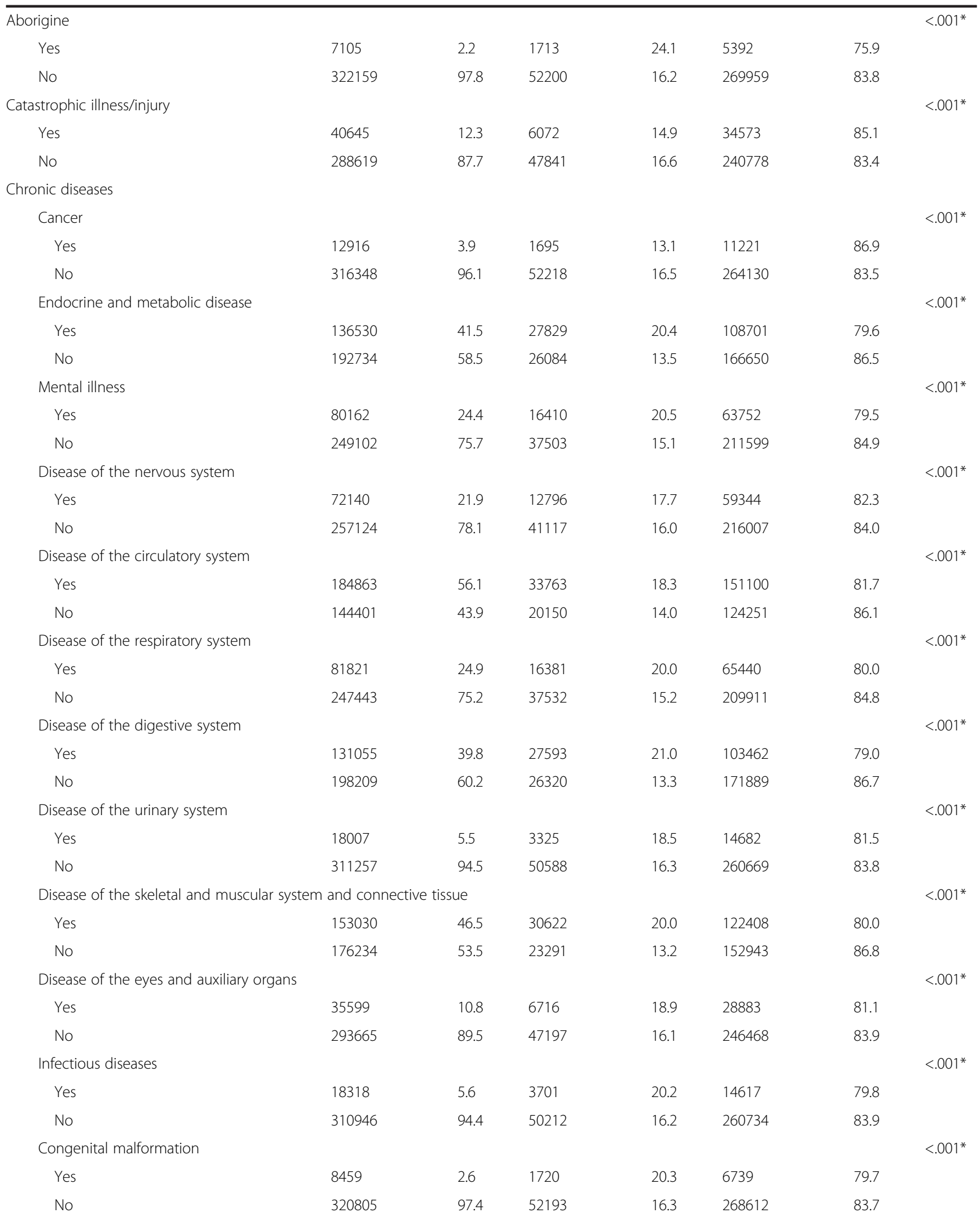


Table 1 Use of adult preventive health services among the physical disability: basic characteristics and bivariate analysis (Continued)

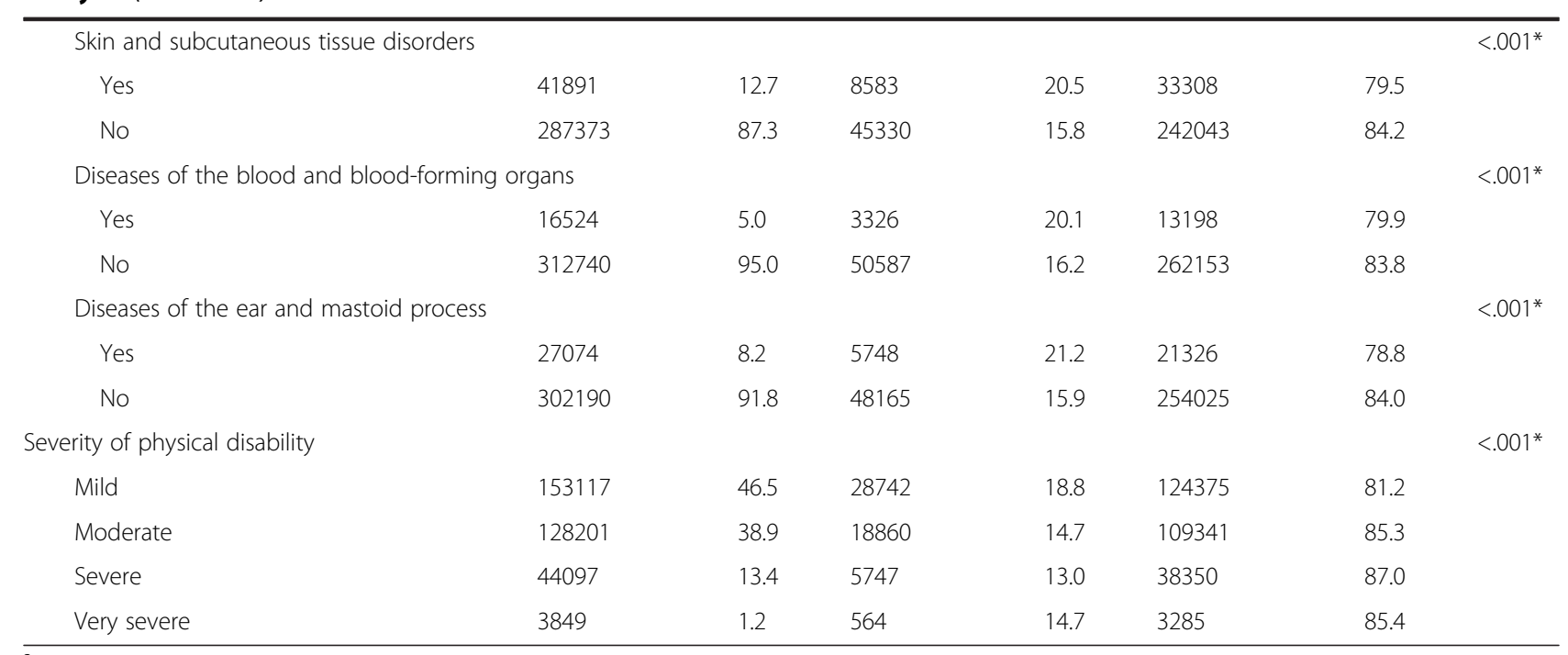

aLevel one: the most urbanized areas.

${ }^{*} \mathrm{P}<0.05$.

only had 0.46 times that of the 40 to 44 age group $(\mathrm{OR}=$ $0.46,95 \% \mathrm{CI}=0.44-0.48)$. There were significant differences between urban and rural life. Utilization by those in Level 8 areas (rural) was 1.72 times higher $(\mathrm{OR}=1.72$, 95\% CI $=1.63-1.82$ ) than by those in Level 1 areas (urban). Using the lowest monthly insured payroll (i.e., less than NT $\$ 15,840)$ as a reference, the NT $\$ 30,300$ to 36,300 group had 1.27 times the utilization rate of the reference group (OR $=1.27,95 \% \mathrm{CI}=1.21-1.33)$.

Those with aboriginal status had a higher utilization rate, which was 1.21 times higher than that of nonaborigines $(\mathrm{OR}=1.21,95 \% \mathrm{CI}=1.14-1.28)$. Those with junior college or university educations or above had a utilization rate of only 0.95 times that of those with elementary school educations and below $(\mathrm{OR}=0.95$, 95\% CI, 0.91-0.99). Those who were married had 1.11 times the utilization rate $(\mathrm{OR}=1.11,95 \% \mathrm{CI}=1.07-1.15)$ of those who were unmarried. Those with a catastrophic illness/injury had a lower utilization rate, only 0.86 times $(\mathrm{OR}=0.86,95 \% \mathrm{CI}=0.83-0.89)$ that of those without catastrophic illness/injury.

Relevant chronic diseases (except for cancer, diseases of the nervous system, and diseases of the urinary system, which had less utilization than those who were not afflicted), had a higher utilization rate than those not suffering from relevant chronic diseases. Those with "severe" disability had the lowest utilization rate among the severity of disability categories, which was 0.8 times $(\mathrm{OR}=0.80,95 \% \mathrm{CI}=0.78-0.83)$ that of the "mild" category.

\section{Discussion}

Comparing Taiwan's disabled people's utilization of free adult preventive health care, mental illness was the highest, being 1.47 times that of the physically disabled $(\mathrm{OR}=1.47$, $95 \% \mathrm{CI}=1.37-1.45)$; second was that of the hearing impaired $(\mathrm{OR}=1.22,95 \% \mathrm{CI}=1.19-1.24)$, which was 1.22 times [16] that of the physically disabled. Compared to the free preventive health care utilization rate of all population (34.2\%), the physically disabled had a much lower utilization rate (16.37\%) [28].

This study found that women had a higher free preventive health care utilization rate than did men. This was consistent with the results of previous studies [29-31]. It is possible that women are more concerned with health-related messages, and therefore have a higher utilization rate [32]. For age, the group with the lowest utilization rate was the above-70 group. Whether this was related to elderly handicapped persons mostly living in nursing homes and other institutions [33] or because they have geriatric chronic diseases that cause them to frequently visit hospitals or clinics and not necessary for preventive care remains a valuable topic for future research.

For area of residence, the free preventive health care utilization rates among the physically disabled living in URA Levels 5, 6, 7, and 8 were higher than those living in Levels 1, 2, 3, and 4. Preventive health care utilization rates were higher in rural areas than in urban areas. Although urban areas have closer proximity to care, there are no designated personnel to encourage the public to conduct health checks. Rural areas have a slower pace of living, and people like to participate in free preventive health care with their neighbors. In addition, Taiwan's government has attached importance to the medical gap between urban and rural areas, regularly sending medical patrol vehicles to remote areas to provide medical care and to strengthen 
Table 2 Factors influencing the physical disabled to use adult preventive health services: logistic regression analysis

\begin{tabular}{|c|c|c|c|c|c|c|c|c|}
\hline \multirow[b]{2}{*}{ Variable name } & \multicolumn{4}{|c|}{ Unadjusted } & \multicolumn{4}{|c|}{ Adjusted } \\
\hline & OR & \multicolumn{2}{|c|}{$95 \% \mathrm{Cl}$} & p-value & OR & \multicolumn{2}{|c|}{$95 \% \mathrm{Cl}$} & $p$-value \\
\hline \multicolumn{9}{|l|}{ Gender } \\
\hline Female & 1 & - & - & - & 1 & - & - & - \\
\hline Male & 0.85 & 0.84 & 0.87 & $<.001^{*}$ & 0.82 & 0.80 & 0.84 & $0.001^{*}$ \\
\hline \multicolumn{9}{|l|}{ Age } \\
\hline 40-44 years & 1 & - & - & - & 1 & - & - & - \\
\hline $45-49$ years & 1.18 & 1.13 & 1.23 & $<.001^{*}$ & 1.13 & 1.08 & 1.18 & $<.001^{*}$ \\
\hline 50-54years & 1.37 & 1.31 & 1.43 & $<.001^{*}$ & 1.21 & 1.16 & 1.27 & $<.001^{*}$ \\
\hline 55-59 years & 1.58 & 1.51 & 1.65 & $<.001^{*}$ & 1.25 & 1.19 & 1.31 & $<.001^{*}$ \\
\hline $60-64$ years & 1.87 & 1.79 & 1.96 & $<.001^{*}$ & 1.41 & 1.34 & 1.48 & $<.001^{*}$ \\
\hline 65-69 years & 0.80 & 0.76 & 0.84 & $<.001^{*}$ & 0.55 & 0.52 & 0.58 & $<.001^{*}$ \\
\hline$\geq 70$ years & 0.68 & 0.65 & 0.71 & $<.001^{*}$ & 0.46 & 0.44 & 0.48 & $<.001^{*}$ \\
\hline \multicolumn{9}{|l|}{ Educational level } \\
\hline Elementary school and under & 1 & - & - & - & 1 & - & - & - \\
\hline Junior high school & 1.13 & 1.10 & 1.16 & $<.001^{*}$ & 1.01 & 0.98 & 1.04 & 0.596 \\
\hline Senior (vocational) high school & 1.07 & 1.04 & 1.10 & $<.001^{*}$ & 0.99 & 0.96 & 1.02 & 0.519 \\
\hline Junior college and university or above & 0.89 & 0.85 & 0.92 & $<.001^{*}$ & 0.95 & 0.91 & 0.99 & $0.026^{*}$ \\
\hline Unclear & 0.97 & 0.94 & 1.00 & $0.029^{*}$ & 0.99 & 0.96 & 1.02 & 0.609 \\
\hline \multicolumn{9}{|l|}{ Marital status } \\
\hline Married & 1 & - & - & - & 1 & - & - & - \\
\hline Unmarried & 1.15 & 1.11 & 1.19 & $<.001^{*}$ & 1.11 & 1.07 & 1.15 & $<.001^{*}$ \\
\hline Divorced or widowed & 1.04 & 0.98 & 1.10 & 0.200 & 1.05 & 0.99 & 1.11 & 0.103 \\
\hline Unclear & 1.00 & 0.96 & 1.03 & 0.832 & 0.96 & 0.92 & 1.00 & $0.028^{*}$ \\
\hline \multicolumn{9}{|l|}{ Level of urbanization ${ }^{a}$} \\
\hline Level one & 1 & - & - & - & 1 & - & - & - \\
\hline Level two & 1.51 & 1.45 & 1.58 & $<.001^{*}$ & 1.55 & 1.48 & 1.62 & $<.001^{*}$ \\
\hline Level three & 1.62 & 1.55 & 1.70 & $<.001^{*}$ & 1.67 & 1.60 & 1.75 & $<.001^{*}$ \\
\hline Level four & 1.53 & 1.46 & 1.61 & $<.001^{*}$ & 1.52 & 1.45 & 1.60 & $<.001^{*}$ \\
\hline Level five & 1.76 & 1.69 & 1.84 & $<.001^{*}$ & 1.79 & 1.71 & 1.87 & $<.001^{*}$ \\
\hline Level six & 1.66 & 1.59 & 1.74 & $<.001^{*}$ & 1.69 & 1.61 & 1.77 & $<.001^{*}$ \\
\hline Level seven & 1.77 & 1.69 & 1.85 & $<.001^{*}$ & 1.79 & 1.71 & 1.88 & $<.001^{*}$ \\
\hline Level eight & 1.93 & 1.84 & 2.03 & $<.001^{*}$ & 1.72 & 1.63 & 1.82 & $<.001^{*}$ \\
\hline \multicolumn{9}{|l|}{ Monthly insured payroll } \\
\hline$<15,840$ & 1 & - & - & - & 1 & - & - & - \\
\hline Insured dependents & 0.80 & 0.77 & 0.82 & $<.001^{*}$ & 0.92 & 0.89 & 0.95 & $<.001^{*}$ \\
\hline $16,500-22,800$ & 1.26 & 1.22 & 1.29 & $<.001^{*}$ & 1.19 & 1.15 & 1.23 & $<.001^{*}$ \\
\hline $24,000-28,800$ & 1.54 & 1.47 & 1.60 & $<.001^{*}$ & 1.26 & 1.20 & 1.32 & $<.001^{*}$ \\
\hline $30,300-36,300$ & 1.55 & 1.49 & 1.63 & $<.001^{*}$ & 1.27 & 1.21 & 1.33 & $<.001^{*}$ \\
\hline $38,200-45,800$ & 1.41 & 1.35 & 1.48 & $<.001^{*}$ & 1.17 & 1.11 & 1.23 & $<.001^{*}$ \\
\hline $48,200-57,800$ & 0.85 & 0.79 & 0.90 & $<.001^{*}$ & 0.84 & 0.78 & 0.90 & $<.001^{*}$ \\
\hline
\end{tabular}

Aborigine

No

Yes

1

1.56
1.74

$<.001^{*}$
1.14

1.28

$<.001^{*}$ 
Table 2 Factors influencing the physical disabled to use adult preventive health services: logistic regression analysis (Continued)

\begin{tabular}{|c|c|c|c|c|c|c|c|c|}
\hline \multicolumn{9}{|l|}{ Catastrophic illness/injury } \\
\hline No & 1 & - & - & - & 1 & - & - & - \\
\hline Yes & 0.88 & 0.86 & 0.91 & $<.001^{*}$ & 0.86 & 0.83 & 0.89 & $<.001^{*}$ \\
\hline \multicolumn{9}{|l|}{ Chronic diseases } \\
\hline Cancer & 0.76 & 0.73 & 0.81 & $<.001^{*}$ & 0.87 & 0.82 & 0.93 & $<.001^{*}$ \\
\hline Endocrine and metabolic disease & 1.64 & 1.61 & 1.67 & $<.001^{*}$ & 1.34 & 1.31 & 1.37 & $<.001^{*}$ \\
\hline Mental illness & 1.45 & 1.42 & 1.48 & $<.001^{*}$ & 1.18 & 1.15 & 1.21 & $<.001^{*}$ \\
\hline Disease of the nervous system & 1.13 & 1.11 & 1.16 & $<.001^{*}$ & 0.95 & 0.93 & 0.97 & $<.001^{*}$ \\
\hline Disease of the circulatory system & 1.38 & 1.35 & 1.40 & $<.001^{*}$ & 1.24 & 1.21 & 1.27 & $<.001^{*}$ \\
\hline Disease of the respiratory system & 1.40 & 1.37 & 1.43 & $<.001^{*}$ & 1.22 & 1.19 & 1.25 & $<.001^{*}$ \\
\hline Disease of the digestive system & 1.74 & 1.71 & 1.77 & $<.001^{*}$ & 1.40 & 1.37 & 1.43 & $<.001^{*}$ \\
\hline Disease of the urinary system & 1.17 & 1.12 & 1.21 & $<.001^{*}$ & 0.97 & 0.93 & 1.01 & 0.124 \\
\hline $\begin{array}{l}\text { Disease of the skeletal and muscular } \\
\text { system and connective tissue }\end{array}$ & 1.64 & 1.61 & 1.67 & $<.001^{*}$ & 1.29 & 1.26 & 1.32 & $<.001^{*}$ \\
\hline Disease of the eyes and auxiliary organs & 1.21 & 1.18 & 1.25 & $<.001^{*}$ & 1.02 & 0.99 & 1.05 & 0.200 \\
\hline Infectious diseases & 1.32 & 1.27 & 1.37 & $<.001^{*}$ & 1.11 & 1.06 & 1.15 & $<.001^{*}$ \\
\hline Congenital malformation & 1.31 & 1.25 & 1.39 & $<.001^{*}$ & 1.00 & 0.95 & 1.06 & 0.915 \\
\hline Skin and subcutaneous tissue disorders & 1.38 & 1.34 & 1.41 & $<.001^{*}$ & 1.18 & 1.15 & 1.22 & $<.001^{*}$ \\
\hline Diseases of the blood and blood-forming organs & 1.31 & 1.26 & 1.36 & $<.001^{*}$ & 1.09 & 1.05 & 1.14 & $<.001^{*}$ \\
\hline Diseases of the ear and mastoid process & 1.42 & 1.38 & 1.47 & $<.001^{*}$ & 1.10 & 1.07 & 1.14 & $<.001^{*}$ \\
\hline \multicolumn{9}{|l|}{ Severity of physical disability } \\
\hline Mild & 1 & - & - & - & 1 & - & - & - \\
\hline Moderate & 0.75 & 0.73 & 0.76 & $<.001^{*}$ & 0.84 & 0.82 & 0.86 & $<.001^{*}$ \\
\hline Severe & 0.65 & 0.63 & 0.67 & $<.001^{*}$ & 0.80 & 0.78 & 0.83 & $<.001^{*}$ \\
\hline Very severe & 0.74 & 0.68 & 0.81 & $<.001^{*}$ & 0.92 & 0.84 & 1.01 & 0.082 \\
\hline
\end{tabular}

aevel one: the most urbanized areas.

${ }^{*} \mathrm{P}<0.05$.

publicity. Therefore, those in rural areas have higher preventive health care utilization rates than those in urban areas.

Regarding socioeconomic status, previous studies have shown higher income earners have higher preventive health care utilization rates [34-36]. The study results showed that those with a monthly insured payroll higher than NT $\$ 15,840$ (except for NT $\$ 48,200$ to 57,800 ) have a higher utilization ratio than those earning less than NT 15,840 , which was consistent with previous study results. Those with aboriginal status had a higher utilization rate than did non-aborigines. These results implied that since the majority of aboriginal people live in remote areas, the government assigns medical patrol vehicles to regularly provide medical care and preventive health care in remote areas, and then the aborigine's utilization rate was increased, which reflected the efforts of decreasing the health disparity between residents in urban areas and residents in remote areas. The utilization rate for education level decreased with increases in education. Those with junior college or university or above had the lowest rate. In recent years, various high-end, self-paying preventive health care programs have increased in popularity. Those with junior college or university educations or above and those with monthly insured payroll of NT $\$ 48,200$ to 57,800 have been selecting these high-end, self-paying preventive health care programs because of their higher social economic statuses.

For marital status, married people had a higher adult preventive health care than did unmarried people. These results support the study conducted by Doescher et al. [29]. Married people tend to have more fixed residence and places of medical care than do unmarried people. They have more opportunities to become familiar with health care professionals and are more likely to accept preventive health care through their recommendations or to be informed by health care messages. In addition, married people have stronger social network (e.g., family 
members, relatives, and friends) support than do unmarried people, serving as a reminder for their healthpromoting behaviors $[37,38]$.

For health status, those with a catastrophic illness/injury had a lower utilization rate than did those who did not have a catastrophic illness/injury. This result differed from that of the American behavioral risk factor surveillance system (BRFSS) [39]. Whether this was due to the physically disabled people's catastrophic illnesses/injuries making them weak and less mobile is unknown. Regarding the suffering from related chronic diseases category, those with diseases of the digestive system appeared most frequently. This was similar to the results that $58 \%$ or more of the patients suffered from constipation, onethird had regular abdominal pain, and $62 \%$ had irritable bowel syndrome in a 1998 study on spinal cord injury (SCI) [40]. Regarding the severity of the disability, the greater the level of severity, the lower the probability of preventive health care used. The finding is consistent with that in the study conducted in the United States (2004) [39]. The disabled individuals with higher severity of physical disability would highly depend on assistance of caregivers and leaded to low participation in the preventive health care.

Generally speaking, if the physically disabled people regularly receive free preventive health care, the disease could be early diagnosed and be early treated. If the disease is a minor problem, it could be improved through changes in health behaviors, lifestyle or diet pattern besides necessary medical care received. For the aged people with physical disabilities, if they have chronic diseases, they should visit physicians regularly to treat and control their illnesses. Both regularly receiving preventive health examinations and treating existent diseases are important for the aged and physically disabled people.

\section{Limitations}

In the present study, in order to understand the specific diseases or illness systems influencing the use of preventive health care among the physically disabled people, we included 15 types of chronic diseases as the variable instead of chronic diseases index such as Elixhauser. Thus, this study could not examine the relationship between uses of preventive health care and severity of chronic diseases. In addition, the database did not contain the lifestyle, health beliefs and behaviors of the participants, making further analyses difficult. These were the limitations of this study.

\section{Conclusions}

The study results indicated that the factors that primarily affect physically disabled people's use of preventive adult health care are gender, age, and education, urbanization of the residence area, income, aboriginal status, catastrophic illness and severity of disability.

There is room for improvement regarding free adult preventive health care for catastrophic illness/injury, among those living in urban areas, unmarried people, those with higher education levels, and seniors who are physically disabled. According to these findings, this study recommends the following: (1) to increase accessibility and convenience, medical institutions should strengthen barrier free space planning. Designated service windows, parking, and bathroom facilities should establish for those who are physically disabled to enhance their mobility. (2) Encourage physicians to actively provide preventive health care services for communities and to take the initiative, reminding handicapped people to obtain regular checkups and follow-ups. (3) Preventive health care for handicapped people requires extra time, labor, and costs than for the public. The government should improve the payment of physicians who conduct preventive health care among handicapped people. Their pay should be increased according to the severity of the patient's disability to increase the willingness [41] of physicians to perform preventive health care for handicapped people. (4) The extension of media-based publicity and education for the public and medical institutions for the handicapped is recommended. A study in Taipei in 1998 found that $70 \%$ of those who had not received adult preventive health care did not know about this service [42].

\section{Additional file}

Additional file 1: Range of National Health Insurance Chronic Diseases and ICD-9-code.

\section{Abbreviations}

BRFSS: Behavioral risk factor surveillance system; Cl: Confidence interval; NT \$: New Taiwan Dollar; OR: Odds Ratio; SCl: Spinal cord injury;

URA: Urbanization level of residence area.

\section{Competing interests}

The authors declare that they have no competing interests.

\section{Authors' contributions}

WCT and PTK conducted the study design. SMY drafted the manuscript. PTK and SMY conducted the statistical analysis. WCT is supervisor of the study and revised the manuscript critically for important intellectual content. All authors read and approved the manuscript.

\section{Acknowledgements}

This study was supported by grants (100-asia-21, CMU102-ASIA-12, DOH100TD-B-111-004) from China Medical University, Asia University and the Department of Health. The preventive health care files were obtained from the Bureau of Health Promotion, Department of Health in Taiwan. We are also grateful for use of the National Health Insurance Research Database provided by the Department of Health, Taiwan. The interpretations and conclusions contained herein do not represent those of the Bureau of Health Promotion in Taiwan.

\section{Author details}

${ }^{1}$ Department of Health Services Administration, China Medical University, No. 91 Hsueh-Shih Road, Taichung 40402, Taiwan. ${ }^{2}$ Department of Public Health, China Medical University, Taichung, Taiwan. ${ }^{3}$ Department of 
Chinese Medicine, Nantou Hospita, Nantou, Taiwan. ${ }^{4}$ Department of Healthcare Administration, Asia University, Taichung, Taiwan.

Received: 13 September 2013 Accepted: 17 November 2014 Published online: 05 December 2014

\section{References}

1. Sjolund $\mathrm{BH}$ : Pain and rehabilitation after spinal cord injury: the case of sensory spasticity? Brain Res Brain Res Rev 2002, 40(1-3):250-256

2. Ravenscroft A, Ahmed YS, Burnside IG: Chronic pain after SCl: a patient survey. Spinal Cord 2000, 38(10):611-614.

3. Martz E, Livneh H, Priebe M, Wuermser LA, Ottomanelli L: Predictors of psychosocial adaptation among people with spinal cord injury or disorder. Arch Phys Med Rehabil 2005, 86(6):1182-1192.

4. Balboa-Castillo T, Guallar-Castillon P, Leon-Munoz LM, Graciani A, Lopez-Garcia E, Rodriguez-Artalejo F: Physical activity and mortality related to obesity and functional status in older adults in Spain. Am J Prev Med 2011, 40(1):39-46.

5. Chen $Y$, Henson $S$, Jackson AB, Richards JS: Obesity intervention in persons with spinal cord injury. Spinal Cord 2006, 44(2):82-91.

6. Santiago M, Coyle C: Leisure-time physical activity and secondary conditions in women with physical disabilities. Disabil Rehabil 2004, 26 (8):485-494.

7. Capewell S, Buchan I: Why have sustained increases in obesity and type 2 diabetes not offset declines in cardiovascular mortality over recent decades in Western countries? Nutr Metab Cardiovasc Dis 2012, 22(4):307-311.

8. Cascio G, Schiera G, Di Liegro I: Dietary Fatty acids in metabolic syndrome, diabetes and cardiovascular diseases. Curr Diabetes Rev 2012, 8(1):2-17.

9. Anson CA, Shepherd C: Incidence of secondary complications in spinal cord injury. Int J Rehabil Res 1996, 19(1):55-66.

10. Nosek MA, Robinson-Whelen S, Hughes RB, Petersen NJ, Taylor HB, Byrne MM Morgan R: Overweight and obesity in women with physical disabilities: associations with demographic and disability characteristics and secondary conditions. Disabil Health J 2008, 1(2):89-98.

11. Bauman WA: The potential metabolic consequences of cerebral palsy: inferences from the general population and persons with spinal cord injury. Dev Med Child Neurol 2009, 51(Suppl 4):64-78.

12. Bauman WA, Spungen AM: Coronary heart disease in individuals with spinal cord injury: assessment of risk factors. Spinal Cord 2008, 46(7):466-476.

13. Yekutiel M, Brooks ME, Ohry A, Yarom J, Carel R: The prevalence of hypertension, ischaemic heart disease and diabetes in traumatic spinal cord injured patients and amputees. Paraplegia 1989, 27(1):58-62.

14. Gawne AC, Wells KR, Wilson KS: Cardiac risk factors in polio survivors. Arch Phys Med Rehabil 2003, 84(5):694-696.

15. The Disabled Population by Classification and Grade. In [http://www. mohw.gov.tw/cht/DOS/Statistic.aspx?f_list_no=312\&fod_list_no=4182]

16. Kung PT, Tsai WC, Li YH: Determining factors for utilization of preventive health services among adults with disabilities in Taiwan. Res Dev Disabil 2012, 33(1):205-213.

17. Wolinsky FD, Culler SD, Callahan CM, Johnson RJ: Hospital resource consumption among older adults: a prospective analysis of episodes, length of stay, and charges over a seven-year period. J Gerontol 1994, 49(5):S240-S252.

18. Allen SM, Ciambrone D: Community care for people with disability: blurring boundaries between formal and informal caregivers. Qual Health Res 2003, 13(2):207-226.

19. Van Nostrand JF, Miller B, Furner SE: Selected issues in long-term care: profile of cognitive disability of nursing home residents and the use of informal and formal care by elderly in the community. Vital Health Stat 1993, 3(27):143-185.

20. Anderson G, Knickman JR: Changing the chronic care system to meet people's needs. Health Aff (Millwood) 2001, 20(6):146-160.

21. Maciosek MV, Coffield AB, Flottemesch TJ, Edwards NM, Solberg LI: Greater use of preventive services in U.S. health care could save lives at little or no cost. Health Aff 2010, 29(9):1656-1660.

22. Gandjour A: Aging diseases-do they prevent preventive health care from saving costs? Health Econ 2009, 18(3):355-362.

23. Macnab AJ, Rozmus J, Benton D, Gagnon FA: 3-year results of a collaborative school-based oral health program in a remote First Nations community. Rural Remote Health 2008, 8(2):882.
24. Malach M, Baumol WJ: Opportunities for the cost reduction of medical care. J Community Health 2009, 34(4):255-261.

25. Rodriguez Vazquez C, Garcillan R, Rioboo R, Bratos E: Prevalence of dental caries in an adult population with mental disabilities in Spain. Spec Care Dentist 2002, 22(2):65-69.

26. Healthy People 2020. In [http://healthypeople.gov/2020/ TopicsObjectives2020/pdfs/HP2020_brochure_with_LHI_508.pdf]

27. Huang KH, Tsai WC, Kung PT: The use of Pap smear and its influencing factors among women with disabilities in Taiwan. Res Dev Disabil 2012, 33(2):307-314

28. Adult preventive health care services utilization and providing current service effectiveness analysis study. In [http://www.mmh.org.tw/mmhaff/ file/read/100.02.22 \%E6\%88\%90\%E4\%BA\%BA\%E9\%A0\%90\%E9\%98\%B2\%E4\% BF\%9D\%E5\%81\%A5\%E6\%9C\%8D\%E5\%8B\%99\%E4\%B9\%8B\%E5\%88\%86\% E6\%9E\%90\%E7\%A0\%94\%E7\%A9\%B6.pdf]

29. Doescher MP, Saver BG, Fiscella K, Franks P: Preventive care. J Gen Intern Med 2004, 19(6):632-637.

30. Owens GM: Gender differences in health care expenditures, resource utilization, and quality of care. J Manag Care Pharm 2008, 14(3 Suppl):2-6.

31. Bertakis KD, Azari R, Helms LJ, Callahan EJ, Robbins JA: Gender differences in the utilization of health care services. J Fam Pract 2000, 49(2):147-152.

32. Horch K, Wirz J: People's interest in health information. Bundesgesundheitsblatt Gesundheitsforschung Gesundheitsschutz 2005, 48(11):1250-1255.

33. Haveman M, Perry J, Salvador-Carulla L, Walsh PN, Kerr M, Van Schrojenstein Lantman-de Valk H, Van Hove G, Berger DM, Azema B, Buono S: Ageing and health status in adults with intellectual disabilities: results of the European POMONA II study. J Intellect Dev Disabil 2011, 36(1):49-60.

34. Katz SJ, Hofer TP: Socioeconomic disparities in preventive care persist despite universal coverage: breast and cervical cancer screening in Ontario and the United States. JAMA 1994, 272(7):530-534.

35. Rodriguez MA, Ward LM, Perez-Stable EJ: Breast and cervical cancer screening: impact of health insurance status, ethnicity, and nativity of Latinas. Ann Fam Med 2005, 3(3):235-241.

36. Hewitt M, Devesa SS, Breen N: Cervical cancer screening among U.S. women: analyses of the 2000 National Health Interview Survey. Prev Med 2004, 39(2):270-278.

37. Goldman N, Korenman S, Weinstein R: Marital status and health among the elderly. Soc Sci Med 1995, 40(12):1717-1730.

38. Suarez L, Lloyd L, Weiss N, Rainbolt T, Pulley L: Effect of social networks on cancer-screening behavior of older Mexican-American women. J Natl Cancer Inst 1994, 86(10):775-779.

39. Diab ME, Johnston MV: Relationships between level of disability and receipt of preventive health services. Arch Phys Med Rehabil 2004 85(5):749-757

40. De Looze D, Van Laere M, De Muynck M, Beke R, Elewaut A: Constipation and other chronic gastrointestinal problems in spinal cord injury patients. Spinal Cord 1998, 36(1):63-66.

41. Tsai WC, Kung PT, Chiang HH, Chang WC: Changes and factors associated with dentists' willingness to treat patients with severe disabilities. Health Policy 2007, 83(2-3):363-374.

42. Ho LL: The utilization and its determinants of adult preventive care under National Health Insurance- a case in Taipei. In Master thesis. Taipei: Department of Public Health, National Taiwan University; 1998.

doi:10.1186/s12913-014-0610-5

Cite this article as: Yen et al:: Factors associated with free adult preventive health care utilization among physically disabled people in Taiwan: nationwide population-based study. BMC Health Services Research 2014 14:610. 